\title{
Modulation of viral infection in plants by exogenous guanosine
}

\author{
Alessandra Panattoni ${ }^{1} \cdot$ Enrico Rinaldelli $^{2} \cdot$ Alberto Materazzi $^{1} \cdot$ Andrea Luvisi $^{1}$
}

Received: 8 May 2015/Revised: 7 July 2015/Accepted: 1 October 2015/Published online: 8 October 2015

(C) Franciszek Górski Institute of Plant Physiology, Polish Academy of Sciences, Kraków 2015

\begin{abstract}
To evaluate the role of purines in antiviral treatments in plants, ribavirin (RB) and tiazofurin (TZ) were applied in combination with guanosine (GS) or adenosine (AS) in in vitro grapevine or tobacco explants infected by Grapevine leafroll associated virus 3 (GLRaV3 ) and Cucumber mosaic virus (CMV), respectively. Using a microelectrochemical (trans-plasma membrane electron transport, t-PMET) technique, in vivo assay of free reduced nicotinamide adenine dinucleotide (NADH) was also carried out to estimate the inosine monophosphate dehydrogenase inhibition caused by drugs. Antiviral effectiveness of TZ, evaluated as virus-free explants or virus copies, was significantly hindered by GS in both species, while AS did not interfere with the drugs. GS, but not AS, slightly hindered the antiviral effectiveness of RB. With regard to NADH tests, t-PMET inhibition caused by RB and TZ was dose dependent and the interference of drugs with the $\mathrm{NAD}^{+} / \mathrm{NADH}$ conversion was confirmed by NADH content. Findings indicate that exogenous GS up to $0.50 \mathrm{mM}$ replenished the GS pool depleted by drugs, contrasting antiviral action. At higher doses of GS, the TZ antiviral action was completely inhibited and exogenous GS caused a feedback that reduced t-PMET activity. The reversal was partially against $R B$, suggesting that the reduction of the
\end{abstract}

Communicated by E. K.-Gebarowska.

Andrea Luvisi

aluvisi@agr.unipi.it

1 Department of Agriculture, Food and Environment, University of Pisa, Via del Borghetto, 80, 56124 Pisa, Italy

2 Department of Agrifood Production and Environmental Sciences, sect. Arboriculture, Laboratory of Electrophysiology, University of Florence, Viale delle Idee, 30, 50019 Sesto Fiorentino, Florence, Italy
GS pool contributed to the antiviral activity of RB, but it was not the only cause of antiviral effectiveness.

Keywords t-PMET - Ribavirin - Tiazofurin - GLRaV-3 . CMV

\begin{tabular}{ll}
\multicolumn{2}{l}{ Abbreviation } \\
RB & Ribavirin \\
TZ & Tiazofurin \\
GS & Guanosine \\
AS & Adenosine \\
GLRaV-3 & Grapevine leafroll associated virus 3 \\
CMV & Cucumber mosaic virus \\
t-PMET & Trans-plasma membrane electron transport \\
NADH & Nicotinamide adenine dinucleotide
\end{tabular}

\section{Introduction}

For the biosynthesis of guanine nucleotides needed for translation, transcription and replication processes (Allison and Eugui 2000), inosine monophosphate dehydrogenase (IMPDH) is a key enzyme. In animals, it is believed that IMPDH inhibition affects not only the proliferation of eukaryotic cells but also replication of DNA and RNA (Markland et al. 2000). Some IMPDH inhibitors are derived from the structure of ribavirin $(\mathrm{RB})$, a synthetic nucleoside analog of guanosine (GS), and this class of molecules has marked antiviral activity. Indeed, many molecules have been tested in this regard, for example tiazofurin (TZ). IMPDH inhibitors are crucial for the transcription of triphosphate ribonucleotides, and as such are central to final inhibiting stages of nucleic acid 
replication in viruses. In animal cells, the main target of these molecules in terms of antiviral activity is IMPDH and the action of its inhibitor reduces the intracellular pool of GS which also prevents the synthesis of viral RNA (Franchetti et al. 1996).

Several investigators (Nascimento et al. 2003; Guta et al. 2010; Panattoni et al. 2013a, 2014; Skiada et al. 2013; Guazzelli et al. 2015) have found that some animal IMPDH inhibitors have antiviral activity in plants and, based on the data, the mechanism of antiviral action found in animals can occur in plants as well. This fact highlights the important role of IMPDH in viral replication. In animals, IMPDH is considered to be an NAD-dependent enzyme that controls the de novo synthesis of purine (Petrelli et al. 2013). Studies have found a correlation between virus infection and higher NADH contents: via a microelectrochemical technique to measure trans-plasma membrane electron transports (t-PMET), this parameter can be assayed in plant tissues and in vivo cells (Taylor and Chow 2001; Luvisi et al. 2012). t-PMET are targets for the development of antiviral drugs as they permit extracellular oxidants to be reduced at the expense of cellular reducing equivalents that may derive from NADH (Del Principe et al. 2011). Panattoni et al. (2013b) found that t-PMET activity in plants was diminished by IMPDH inhibitors, which suggests that inhibitors interfere with the $\mathrm{NAD}^{+}$/ NADH conversion.

GS reversed the antiviral effectiveness of drugs such as RB in animal cells, suggesting that inhibition of IMPDH, and thus depletion of the intracellular guanosine triphosphate (GTP) pool (Takhampunya et al. 2006; Mitsuhashi et al. 2010), may be one mode of antiviral action. In addition, GS reversed the apoptotic effect of IMPDH inhibitor gnidilatimonoein in K562 cells (Nouri et al. 2011).

This paper reports the application of $\mathrm{RB}$ and $\mathrm{TZ}$ in combination with GS and AS in in vitro grapevine or tobacco explants infected by viruses [(Grapevine leafroll associated virus 3 (GLRaV-3) or Cucumber mosaic virus $(\mathrm{CMV})]$ to evaluate the modulation of viral infection by exogenous purines. The effects of $\mathrm{NAD}^{+} / \mathrm{NADH}$ conversion caused by IMPDH inhibition were also evaluated using an in vivo assay.

\section{Materials and methods}

\section{Plant materials}

In vitro grapevine explants were obtained following the Panattoni et al. (2007) protocol from field-grown V. vinifera cv. Sangiovese naturally infected singularly by GLRaV-3 and virus-free $V$. vinifera cv. Sangiovese plants, considering viruses included in the European Commission directive 2005/43/EC. Leafroll disease is an economically harmful graft-transmissible disease of grapevines and occurs in all grapevine-growing countries (Cabaleiro et al. 2008). An analogous procedure was carried out to obtain in vitro Nicotiana tabacum cv. Turkish explants artificially infected by CMV, while healthy plants were used as control. Nodes were collected and surface sterilized before transfer to aseptic culture tubes with fresh Murashige and Skoog (1962) or Quoirin and Lepoivre (1977) proliferating media for tobacco and grapevine, respectively. All explants were maintained in a controlled environment chamber that assured maintenance of sanitary conditions, with a temperature regime of $22 \pm 1{ }^{\circ} \mathrm{C}, 16 \mathrm{~h}$ photoperiod, $50 \mu \mathrm{Em}^{-2} \mathrm{~s}^{-1}$. Explants were transferred to fresh proliferating medium at 15- and 30-day intervals for tobacco and grapevine, respectively. After an acclimatization period, the sanitary condition of each plantlet was confirmed by RT-PCR. Total RNA was extracted from grapevine or tobacco samples according to the methods described by MacKenzie et al. (1997) and RNA was detected using a one-step RT-PCR procedure based on the One Step RTPCR kit (Qiagen, Hilden, Germany). DNA primer pairs for amplification were those designed by Bertolini et al. (2003) for CMV and Turturo et al. (2005) for GLRaV-3.

\section{Chemical treatments}

To evaluate the effectiveness of chemicals on health status, $\mathrm{RB}, \mathrm{TZ}$, GS or AS were hydrated in stock solution and, immediately before use, ultra-filtered and added to the proliferation medium after sterilization. Toxicity tests were carried out on healthy tobacco and grapevine explants subjected to several drug concentrations $(0.00,0.10,0.20$, $0.30,0.40 \mathrm{mM}$ ) for three repeated subcultures. The toxic threshold for an acceptable mortality rate was set at $30 \%$ dead explants. The experimental design involved drug administration (solo or mixed) for six consecutive subcultures, for a total treatment time of 90 and 180 days for tobacco and grapevine, respectively. After each treatment, the apical portion $(1-2 \mathrm{~cm})$ of each explant was transferred to fresh supplemented medium and the residue was assayed by RT-PCR. Tests were repeated after 6 months to confirm virus elimination. Antiviral effectiveness was expressed as virus-free explants after six subcultures of treated explants. RT-qPCR was also performed to assess GLRaV-3 and CMV copies in explants. Specific primers based on the RNA-dependent RNA polymerase (RdRp) domains of GLRaV-3 and CMV were used (Feng et al. 2006; Velasco et al. 2014). Relative quantitations of viruses were achieved by normalization of data to the concentration (Tsai et al. 2013; Velasco et al. 2014). Infection level was expressed as virus copies in treated explants compared to control (\%). 


\section{Electrophysiological measurements}

For the in vivo amperometric measurements, carbon fiber microelectrodes (CFME) (tip diameter $5 \mu \mathrm{m}$ ) (Carbostar-1, Kation Scientific, USA) were used following Rinaldelli et al. (2012). CFME were used in subsequent calibrations to test the linear response in the presence of the redox intermediary. Electrodes were placed in recording solution (RS) with a constant background of $5 \times 10^{-4} \mathrm{M}$ potassium ferricyanide $\left(\mathrm{K}_{3}\left[\mathrm{Fe}(\mathrm{CN})_{6}\right]\right)$ (PF) adjusted to $\mathrm{pH} 5.6$ by MES (2-(N-Morpholino)ethanesulfonic acid), and varying concentrations of potassium ferrocyanide $\left(\mathrm{K}_{4}\left[\mathrm{Fe}(\mathrm{CN})_{6}\right]\right)$ $(0,20,50,100 \mu \mathrm{M})$. The oxidation current, at an electrode potential of $+400 \mathrm{mV}$, was measured for each potassium ferrocyanide concentration. The current at the CFME surface rises because the impermeable intermediary ferrocyanide, generated by the reduction of ferricyanide by the cell reductase activity, is reoxidized by the CFME held at $+400 \mathrm{mV}$. Calibration curves were used to estimate the cell reductase activity expressed as $\left[\mathrm{Fe}^{2+}\right]$ using oxidation current values before each treatment (Rinaldelli et al. 2012). Sample preparation and reductase activity detection were performed following Rinaldelli et al. (2012). To stabilize the system before drug treatments, the leaf sample was maintained in RS until the oxidation current stabilized for at least $5 \mathrm{~min}$. The RS was then extracted using a syringe and renewed, measuring oxidation current until stabilization. The reductase activity difference between RS administrations $\left(\Delta\left[\mathrm{Fe}^{2+}\right]_{\mathrm{RS}}\right.$, \%) was calculated and repeated 15 times. Mean $\Delta\left[\mathrm{Fe}^{2+}\right]_{\mathrm{RS}} \pm \sigma$ was used as threshold to establish system stability before each treatment. Drug treatments came before two sequential administrations of RS which $\Delta\left[\mathrm{Fe}^{2+}\right]_{\mathrm{RS}}$ was set within threshold. Thus, RS was re-extracted via syringe and substituted with drug-RS. Oxidation current was measured until it stabilized for at least 5 min. $\Delta\left[\mathrm{Fe}^{2+}\right]$ for each drug was calculated considering oxidation current after the last RS administration and oxidation current after drug administrations. Measurements were performed under Faraday cage.

NADH was quantified in healthy and infected samples in a colorimetric assay $(450 \mathrm{~nm})$ using NADH Quantification Kit (Sigma-Aldrich, St. Louis, MO, USA).

\section{Statistical analysis}

The effects of treatments on health status, $\Delta\left[\mathrm{Fe}^{2+}\right]$ and NADH were elaborated using Sigma-Plot software (version 11; Systat Software, San Jose, CA, USA). The software was used to perform analysis of variance (ANOVA) in a random design and pairwise multiple comparisons on significant effects and interactions using the Holm-Sidak method. All the experiments were performed in triplicate; each experiment consisted of 15 explants infected with each virus. Data expressed in percent were converted in arcsin values. $P \leq 0.05$ was considered to be significant.

\section{Results and discussion}

With regard to toxicity tests, no mortality in untreated healthy and infected explants was observed due to the micropropagation technique. A less than threshold-toxic effect on healthy explants treated with RB was detected at up to $0.10 \mathrm{mM}$, and up to $0.30 \mathrm{mM}$ for TZ. No toxic effect was found for GS or AS treatments regardless of dosage up to $0.80 \mathrm{mM}$.

The antiviral effectiveness of $\mathrm{TZ}$ was significantly hindered by GS in both species (Fig. 1a, b). GLRaV-3 infected explants were reduced by $37.0 \%$ by TZ and by $7.0 \%$ by $\mathrm{RB}$, compared to the untreated infected control. GS at $0.40 \mathrm{mM}$ reduced antiviral effects, setting activity of TZ and RB at 27.0 and $4.9 \%$, respectively, while AS up to $0.80 \mathrm{mM}$ did not cause a reduction in GLRaV-3 infected explants. Analogous behavior was observed for CMV-infected explants, which were significantly reduced after administration of $\mathrm{TZ}$ and $\mathrm{RB}$ (66.0 and $7.3 \%$, respectively). Activity of $\mathrm{TZ}$ and RB was set at 27.0 and $5.1 \%$, respectively, after $0.40 \mathrm{mM}$ GS administration, while AS caused no effects.

Infection levels followed a similar trend (Fig. 2a, b). GLRaV-3 copies were reduced by $64.3 \%$ by TZ and by $34.3 \%$ by RB, compared to the untreated infected control. GS at $0.40 \mathrm{mM}$ reduced antiviral effects, setting activity of $\mathrm{TZ}$ and $\mathrm{RB}$ at 48.2 and $25.0 \%$ respectively, while AS up to $0.80 \mathrm{mM}$ did not cause a reduction in GLRaV-3 copies. Analogous behavior was observed for CMV copies, which were significantly reduced after administration of $\mathrm{TZ}$ and RB (88.1 and $35.0 \%$, respectively). Activity of TZ and RB was set at 60.6 and $22.8 \%$, respectively, after $0.40 \mathrm{mM} \mathrm{GS}$ administration, while AS caused no effects. CMV and GLRaV-3 copies were unaltered by TZ adding $0.60 \mathrm{mM}$ of GS, while a complete reversal of RB effectiveness was not achieved until $0.80 \mathrm{mM}$ (Fig. 2a, b).

Treatments with RB, TZ or GS caused a significant reduction of t-PMET activity in healthy or infected samples compared to untreated control. Differences were registered among drugs or GS administered at five doses, from $0.00 \mathrm{mM}$ up to a threshold dose $(0.20 \mathrm{mM}$ for RB, $0.40 \mathrm{mM}$ for TZ and $0.80 \mathrm{mM}$ for GS). t-PMET activity of RB-treated samples was significantly reduced compared to the control in both species and regardless of health status (up to 37.5 or $48.4 \%$ in healthy tobacco or grapevine; up to 31.2 or $34.6 \%$ in infected tobacco or grapevine), while the effect of $\mathrm{TZ}$ was milder in the infected samples (up to 23.7 or $8.0 \%$ in tobacco or grapevine). t-PMET activity was slightly reduced after GS administration (up to 11.1 or 


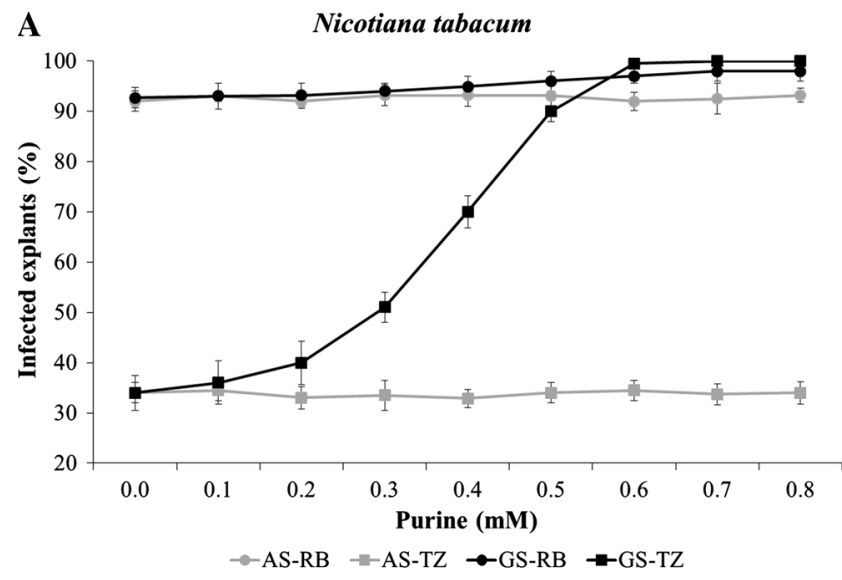

Fig. 1 Effect of different concentrations of guanosine (GS) or adenosine (AS) on effectiveness of ribavirin (RB, $0.10 \mathrm{mM}$ ) or tiazofurin $(\mathrm{TZ}, 0.30 \mathrm{mM})$ on antiviral efficacy (expressed as infected

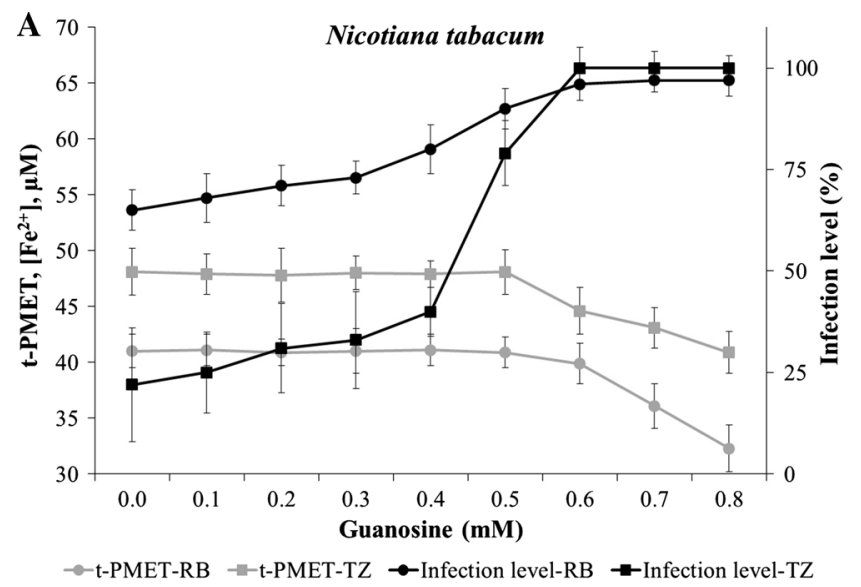

Fig. 2 Effect of different concentrations of guanosine on effectiveness of ribavirin $(\mathrm{RB}, 0.10 \mathrm{mM})$ or tiazofurin $(\mathrm{TZ}, 0.30 \mathrm{mM})$ on trans-plasma membrane potential $\left(\mathrm{t}-\mathrm{PMET}\left(\left[\mathrm{Fe}^{2+}\right], \mu \mathrm{M}\right)\right.$ or infection

$14.0 \%$ in healthy tobacco or grapevine; up to 21.4 or $14.6 \%$ in infected tobacco or grapevine). In any case, t-PMET inhibition caused by RB, TZ or GS was dose dependent.

The inhibitory activity of t-PMET by drugs in healthy or infected grapevine samples was confirmed by NADH content. Infected grapevines showed higher NADH content $(0.74 \pm 0.04)$ compared to healthy ones $(0.54 \pm 0.05)$. A similar behavior was observed in tobacco $(0.55 \pm 0.04$ in infected samples compared to $0.40 \pm 0.04$ in healthy ones). Both drugs applied at less than threshold-toxic concentrations ( $0.10 \mathrm{mM}$ for $\mathrm{RB}, 0.30 \mathrm{mM}$ for $\mathrm{TZ})$ caused a significant $\mathrm{NADH}$ reduction in healthy samples $(-18.5 \%$ for $\mathrm{RB},-16.7 \%$ for $\mathrm{TZ}$ ), while the higher content of NADH in infected plants interfered with drug activity, in particular against TZ $(-5.4 \%$ of NADH content). GS at $0.4 \mathrm{mM}$ caused a $9.3 \%$ decrement in NADH

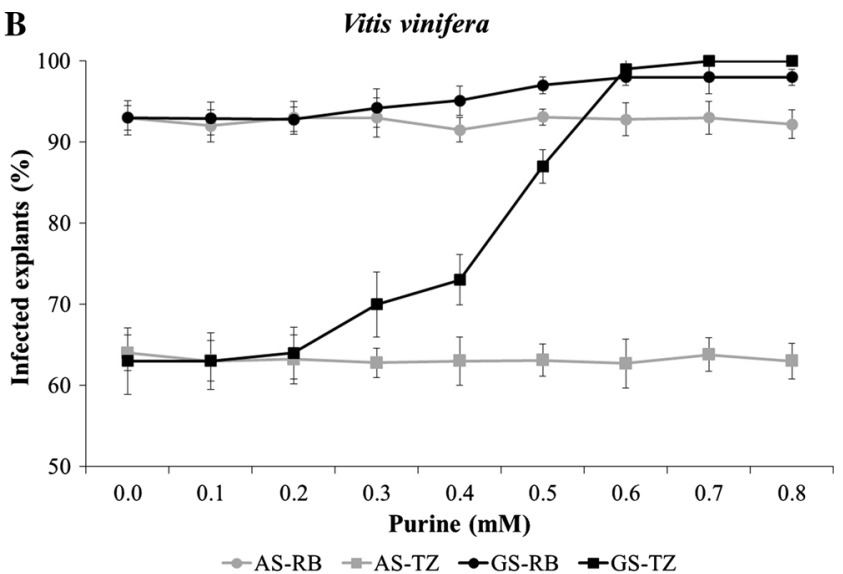

explants after six antiviral subcultures) of in vitro explants of (a) Nicotiana tabacum infected by CMV or (b) Vitis vinifera infected by GLRaV-3

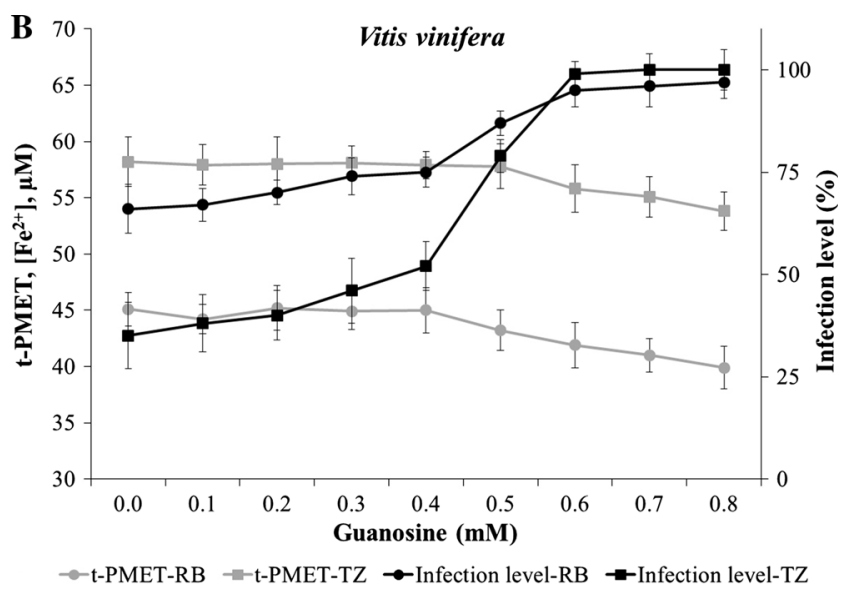

levels (expressed as virus copies in treated explants compared to control) of in vitro explants of (a) Nicotiana tabacum infected by CMV or (b) Vitis vinifera infected by GLRaV-3

when applied alone, slightly enhancing the inhibitory activity of drugs. The same behavior was observed in tobacco samples.

In both species, the addition of GS to RB or TZ treatments did not seem to interfere with t-PMET until the GS administration at $0.50 \mathrm{mM}$ (Fig. 2). At higher dosages, GS reduced t-PMET activity during drug treatments. The GS concentration also represents a threshold with regard to inhibition of antiviral effectiveness expressed as infection level (Fig. 2).

In conclusion, only GS was able to hinder the antiviral properties of both drugs, confirming that $\mathrm{RB}$ or $\mathrm{TZ}$ can interfere with GS pool. RB and TZ can also interfere with $\mathrm{NAD}^{+} / \mathrm{NADH}$ conversion, altering t-PMET activity (Panattoni et al. 2013b). Our tests demonstrate that inhibition of t-PMET by drugs depends on GS addition and its effect is dose dependent, confirming literature data (Glesne 
et al. 1991). Analogous trends were observed considering $\mathrm{NADH}$ tests.

Our results suggest that exogenous GS up to $0.50 \mathrm{mM}$ replenishes the GS pool depleted by drugs, contrasting antiviral action. At higher dosages, the $\mathrm{TZ}$ antiviral action was completely inhibited and exogenous GS caused a feedback that reduced t-PMET activity. The exogenous GS effect was partially against RB, suggesting that reduction of the GS pool contributed to the antiviral activity of RB, but it was not the only cause of antiviral effectiveness as was also found in Vero cells (Sepúlveda et al. 2012).

Author contribution statement All authors contributed equally to this work. All authors designed and instructed the research work. All authors performed the experiments and analyzed data. Andrea Luvisi and Alessandra Panattoni prepared the manuscript. Enrico Rinaldelli and Alberto Materazzi edited the manuscript. All authors discussed the results and implications and commented on the manuscript at all stages.

\section{Compliance with ethical standards}

Conflict of interest The authors declare that they have no conflict of interest.

\section{References}

Allison AC, Eugui EM (2000) Mycophenolate mofetil and its mechanisms of action. Immunopharmacology 47:85-118

Bertolini E, Olmos A, López MM, Cambra M (2003) Multiplex nested reverse transcription-polymerase chain reaction in a single tube for sensitive and simultaneous detection of four RNA viruses and Pseudomonas savastanoi pv. savastanoi in olive trees. Phytopathology 93:286-292

Cabaleiro C, Couceiro C, Pereira S, Cid M, Barrasa M, Segura A (2008) Spatial analysis of epidemics of Grapevine leafroll associated virus-3. Eur J Plant Pathol 121:121-130

Del Principe D, Avigliano L, Savini I, Catani MV (2011) Transplasma membrane electron transport in mammals: functional significance in health and disease. Antioxid Redox Sign 14:2289-2318

Feng JL, Che SN, Tang XS, Ding XF, Du ZY, Chen JS (2006) Quantitative determination of cucumber mosaic virus genome RNAs in virions by real-time reverse transcription-polymerase chain reaction. Acta Bioch Bioph Sin 38:669-676

Franchetti P, Capellacci L, Grifantini M (1996) IMP dehydrogenase as a target of antitumor and antiviral chemotherapy. Il Farmaco 51:457-469

Glesne DA, Collart FR, Huberman E (1991) Regulation of IMP dehydrogenase gene expression by its end products, guanine nucleotides. Mol Cell Biol 11:5417-5425

Guazzelli L, D’Andrea F, Giorgelli F, Catelani G, Panattoni A, Luvisi A (2015) Synthesis of PAMAM dendrimers loaded with mycophenolic acid to be studied as new potential immunosuppressants. J Chem 2015. doi:10.1155/2015/263072

Guta IC, Buciumeanu EC, Gheorghe RN, Teodorescu A (2010) Solutions to eliminate grapevine leafroll associated virus serotype $1+3$ from $V$. vinifera $L$. cv. Ranai Magaraci. Rom Biotech Lett 15:72-78
Luvisi A, Rinaldelli E, Panattoni A, Triolo E (2012) Membrane transport of antiviral drugs in plants: an electrophysiological study in grapevine explants infected by Grapevine leafroll associated virus 1. Acta Physiol Plant 34:2115-2123

MacKenzie DJ, McLean MA, Mukerji S, Green M (1997) Improved RNA extraction from woody plants for the detection of viral pathogens by reverse transcription-polymerase chain Reaction. Plant Dis 81:222-226

Markland W, McQuaid TJ, Jain J, Kwong AD (2000) Broadspectrum antiviral activity of the IMP dehydrogenase inhibitor VX-497: a comparison with ribavirin and demonstration of antiviral additivity with alpha interferon. Antimicrob Agents Chemother 44:859-866

Mitsuhashi S, Takenaka J, Iwamori K, Nakajima N, Ubukat M (2010) Structure-activity relationships for inhibition of inosine monophosphate dehydrogenase and differentiation induction of K562 cells among the mycophenolic acid derivatives. Bioorgan Med Chem 18:8106-8111

Murashige T, Skoog F (1962) A revised medium for rapid growth and bioassays with tobacco tissue cultures. Physiol Plant 15:473-497

Nascimento LC, Pio Ribeiro G, Willadino L, Andrade GP (2003) Stock indexing and Potato Virus $\mathrm{Y}$ elimination from potato plants cultivated in vitro. Sci Agric 60:525-530

Nouri K, Yazdanparast R, Sarafnejad A (2011) Guanosine supplementation reduces the antiproliferative and apoptotic effects of the IMPDH inhibitor gnidilatimonoein in K562 cells. Cell Biol Int 35:1001-1008

Panattoni A, D'Anna F, Triolo E (2007) Antiviral activity of tiazofurin and mycophenolic acid against Grapevine Leafroll associated Virus 3 in Vitis vinifera explants. Antivir Res 73:206-211

Panattoni A, Luvisi A, Triolo E (2013a) Elimination of viruses in plants: twenty years of progress. Span J Agric Res 11:173-188

Panattoni A, Rinaldelli E, Triolo E, Luvisi A (2013b) In vivo inhibition of trans-plasma membrane electron transport by antiviral drugs in grapevine. J Membr Biol 246:513-518

Panattoni A, Luvisi A, Fuselli S, D'Andrea F, Giorgelli F, Guazzelli L, Catelani G, Triolo E (2014) Antiviral activity of mycophenolic acid derivatives in plants. Acta Virol 58:99-102

Petrelli R, Vita P, Torquati I, Felczak K, Wilson DJ, Franchetti P, Cappellacci L (2013) Novel inhibitors of Inosine monophosphate dehydrogenase in patent literature of the last decade. Recent Pat Anti-Cancer 8:1-23

Quoirin M, Lepoivre P (1977) Etude de millieux adaptes aux cultures in vitro de prunus. Acta Hortic 78:437-442

Rinaldelli E, Panattoni A, Luvisi A, Triolo E (2012) Effect of mycophenolic acid on trans-plasma membrane electron transport and electric potential in virus-infected plant tissue. Plant Physiol Bioch 60:137-140

Sepúlveda CS, García CC, Fascio ML, D’Accorso NB, Docampo Palacios ML, Pellón RF, Damonte EB (2012) Inhibition of Junin virus RNA synthesis by an antiviral acridone derivative. Antivir Res 9:16-22

Skiada FG, Maliogka VI, Katis NI, Eleftheriou EP (2013) Elimination of Grapevine rupestris stem pitting-associated virus (GRSPaV) from two Vitis vinifera cultivars by in vitro chemotherapy. Eur J Plant Pathol 135:407-414

Takhampunya R, Ubol S, Houng HS, Cameron CE, Padmanabhan R (2006) Inhibition of dengue virus replication by mycophenolic acid and ribavirin. J Gen Virol 87:1947-1952

Taylor AR, Chow RH (2001) A microelectrochemical technique to measure transplasma membrane electron transport in plant tissue and cells in vivo. Plant Cell Environ 24:749-754

Tsai CW, Daugherty MP, Almeida RPP (2013) Seasonal dynamics and virus translocation of Grapevine leafroll-associated virus 3 in grapevine cultivars. Plant Pathol 61:977-985 
Turturo C, Saldarelli P, Yafeng D, Digiaro M, Minafra A, Savino V, Martelli GP (2005) Genetic variability and population structure of grapevine leafroll-associated virus 3 isolates. J Gen Virol $86: 217-224$
Velasco L, Bota J, Montero R, Cretazzo E (2014) Differences of three Ampeloviruses' multiplication in plant may explain their incidences in vineyards. Plant Dis 98:395-400 